\title{
DEM 2007 Editorial
}

\author{
Stefan Luding • Paul Cleary
}

Received: 2 June 2009 / Published online: 2 July 2009

(C) The Author(s) 2009. This article is published with open access at Springerlink.com

\section{DEM 2007: 4th International Conference on Discrete Element Methods}

Conference website: http://www.min-eng.com/dem07/

\section{Guest Editors for this special issue}

\section{Stefan Luding}

Multi Scale Mechanics, CTW, UTwente

P.O. Box 217, 7500 AE Enschede, The Netherlands

Tel.: +31-53-4894212

e-mail: s.luding@utwente.nl

http://www2.msm.ctw.utwente.nl/sluding/

\section{Paul Cleary}

Leader, Computational Modelling

CSIRO Mathematical and Information Sciences

Phone: +61-3-95458005

e-mail: Paul.Cleary@csiro.au

http://www.csiro.au/people/Paul.Cleary.html

Conference dates:

Monday 27 August to Wednesday 29 August 2007

Location: Brisbane Hilton, Australia

\section{Organising Committee:}

- Dr Paul Cleary, Chairman (CSIRO)

- Dr Gideon Chitombo (UQ/SMI)

- Dr Rob Morrison (UQ/JKMRC)

\section{S. Luding $(\varangle)$}

Multi Scale Mechanics, CTW, UTwente, P.O. Box 217,

7500 AE, Enschede, The Netherlands

e-mail: s.luding@utwente.nl

URL: http://www2.msm.ctw.utwente.nl/sluding/

\section{P. Cleary}

Computational Modelling, CSIRO Mathematical

and Information Sciences, Clayton, Australia

e-mail: Paul.Cleary@csiro.au

URL: http://www.csiro.au/people/Paul.Cleary.html
Conference Logistics:

Dr Barry Wills, Minerals Engineering International, http://www.min-eng.com

Discrete element methods (DEM) are a suite of numerical techniques developed over the past 30 years to model granular materials, rock, and other discontinuous materials at the grain scale. The motion of particulates and the deformation of solids are dominated by the contact forces between bodies. The prediction of these forces and the subsequent evolution of the particulate system is the basis of the DEM methods. DEM is increasingly coupled to other important physics such as fluid motion, material deformation, and fracture.

The DEM 2007 conference was the fourth in the series and was dedicated to bringing together leading researchers from the many scientific disciplines and application areas that are spanned by these discrete computational methods. The three previous conferences were held in the USA, in Golden, Colorado in 1989, Cambridge, Massachusetts in 1993 and Santa Fe, New Mexico in 2002.

The conference dealt with all aspects of:

- The numerical schemes that drive DEM, including coupling to other methods

- Experimental validation of predictions

- Contact force, cohesion and breakage models

- All applications of DEM including industrial applications.

These were organized into four broad themes:

- Theme 1: Numerical methods, Validation and Novel Applications

- Theme 2: Powder Technology, Process Engineering and Industrial Applications

- Theme 3: Mining, Geomechanics and Geophysics

- Theme 4: Mineral and Physical Processing 
This special issue deals mostly with the Theme 1: Numerical methods, Validation and Novel Applications. The seven papers include DEM results involving spherical and nonspherical particles. New algorithms for particle contacts, their rotation, and non-spherical objects are introduced, and stateof-the-art methods for parameter identification are presented. The systems studied involve small-scale shear-banding, vibrated beds, and large scale industrial applications such as a blast-furnace.

The conference hosted the first DEM Gallery organized by Prof. Dr. Mark Sawley (from EPFL, Switzerland), in which images submitted by the DEM community were assessed on both their artistic and scientific content. The posters from the DEM Gallery as well as the guidelines, the contributors and the awards, can be found on the MEI web site at: http://www. min-eng.com/dem07/gallery/DEM_Gallery/Home.html

Anyone wishing to get a copy of the DEM07 CD can find details of how to order them at http://www.min-eng.com/ dem07/paps.html

Enschede and Melbourne, June, 2009

\section{Stefan Luding and Paul Cleary}

Open Access This article is distributed under the terms of the Creative Commons Attribution Noncommercial License which permits any noncommercial use, distribution, and reproduction in any medium, provided the original author(s) and source are credited. 